\title{
Analytical model for assessing the investments in connectivity for small airports
}

\author{
Cătălin Cioacă ${ }^{1, *}$, Mircea Boșcoianu ${ }^{1}$, Dănuţ Bălos ${ }^{2}$, and Doru Luculescu ${ }^{3}$ \\ 1 "Henri Coandă" Air Force Academy, FSM Department, 160 M. Viteazul, Brașov, Romania \\ ${ }^{2}$ Transilvania University of Brasov, Department of EIM, 5 M. Viteazul, Brașov, Romania \\ 3 "Henri Coandă" Air Force Academy, Av Department, 160 M. Viteazul, Brașov, Romania
}

\begin{abstract}
The purpose of the research is to develop a model for the analysis of investments in connectivity. The developed model allows a more accurate capture of the impact of sources of fluctuations in investment projects aimed at increasing connectivity, using Wiener Processes and Poisson distribution. The results are solutions for improved decision-making in aviation infrastructure to the benefit of the regional economy.
\end{abstract}

\section{Introduction}

The interest on investment impact assessment theories have increased in recent years due to the high degree of uncertainty faced by some organizations (private sector and public) where the decision to make a strategic investment is required (competitive environment) or is a requirement external of the organizational environment (providing new standards).

Designing an investment in air transport architecture should take into account: direct costs (e.g. acquisition, operation, maintenance), indirect and intangible costs (e.g. increasing waiting time, affecting the right to privacy) and benefits (e.g. increasing number of passengers).

The principle of assessment in case of neutrality towards risk can be used to evaluate an investment project that depends on an extensive set of variables. For each variable, the expected growth rate is adjusted in order to reflect the price risk resulting from market mechanisms.

Impairment of investments is inherent and leads to the following dilemma: low and frequent investments or major investment and rare ones. Uncertainty, irreversibility, growth potential and competition are factors that influence behavior and investment decision [1].

By analogy with the market, the air transport system can be viewed as a network of airport organizations (system elements) interdependent where the motivation to invest increases if the other elements of the network system succeed in doing the same thing. The possibility of contagion investment is based on two arguments: contagion proximity of benefits (important economic benefits can be obtained from high commercial air service

* Corresponding author: catalin.cioaca@afahc.ro 
connected); proximity contagion security (which is the critical mass of network system elements that must invest in order to persuade others to do the same).

From an economic perspective, small regional airports frequently suffer from limited traffic, fixed infrastructure requirements and insufficient revenues to cover their costs [2]. In this context, the research question is: How connectivity should sustain these small airports in order to survive in the emergence of multiple sources of jump risk?

The paper is organized as follows. First, we offer a brief overview of the existing airport network in Romania. Then, the functioning of airports is examined with regard to the connectivity parameters. In section 4 the impact of fluctuations' sources in investment projects is analyzed, considering independent jumps as size and appearance time. The results of the analysis, with a particular focus on newly developed regional airports, are presented in section 5. Finally, we debate model's limitations and possible directions for future research.

\section{Overview of airport network in Romania}

As of 2018, Romania has 17 airports certified [3], twelve of which are part of the transEuropean transport network (TEN-T). The air transport in Romania has experienced rapid growth in the last years (Fig. 1): 3,493 million in 2005; 9,674 million in 2012 [4]; 20.2 million in 2017 [5].

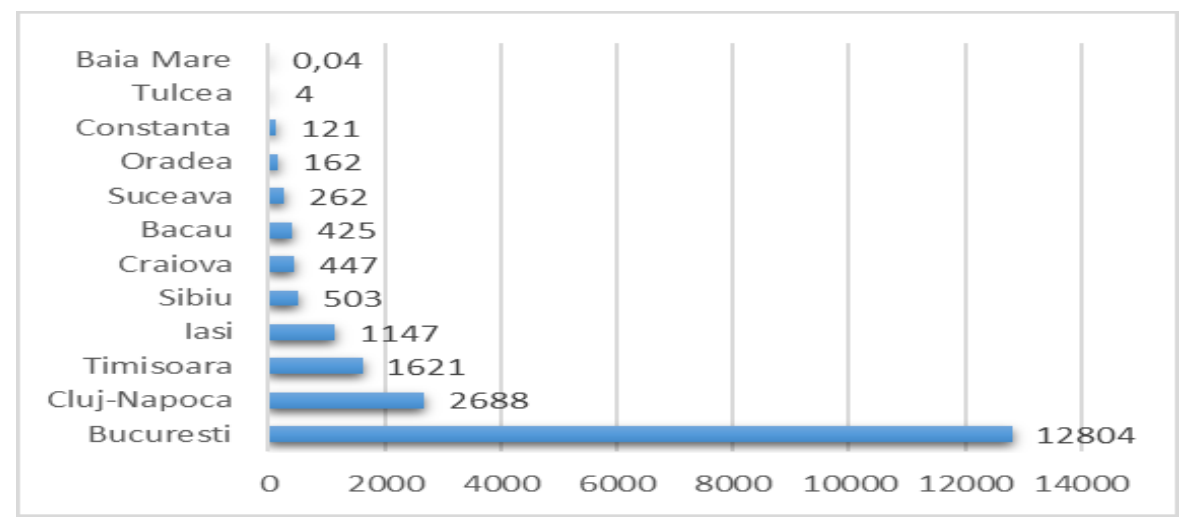

Fig. 1 Romanian TEN-T airports depicted by numbers of passengers in 2017 (thousands)

Also the volume of goods transported has had a similar trend, increasing by over $60 \%$. However, air travel represents only $3 \%$ of the total passengers' traffic and $1 \%$ of the freight traffic [3].

Of the 13 airports included in the TEN-T, 2 are under government control, and 11 were transferred to the ownership and control of local authorities (county council). Decentralization argument was the reorganization/liberalization of the air transport market. This transfer was a challenge, especially a financial one, for the local authorities while the outdated and requires significant investment in order to satisfy the current and near future requirements. Due to the high potential of airport infrastructure in attracting investments and business activity, the Brasov county council has decided to build an airport, based on public - private partnership. Brasov is the only major city within Romania without an airport, even though a sum of indicators recommends building one: it has a sufficiently large catchment area (160 km to Bucharest, $140 \mathrm{~km}$ to Sibiu, $170 \mathrm{~km}$ to Târgu Mureș); it is the most important tourist city in Romania with a great growth potential (e.g. tourists accommodation capacity increased in 2013 by $60 \%$ compared to 2009 , it is a candidate to 
the title of European Capital of Culture); it is a city with a long tradition in the aviation industry (IAR factory established in 1925); demographic potential of the area.

\section{Dimensions of connectivity}

A large number of international studies confirm the importance of connectivity in air transport networks for regional economic development and also in order to boost national and international investments $[6,7,8,9]$. The concept of connectivity is defined in terms of integration of an airport or regional network in the global air transport network. In Table 1 it is listed the most frequently used and cited connectivity indicators.

Table 1. Connectivity indicators and studies

\begin{tabular}{|c|c|c|c|}
\hline Indicator & Formula & $\begin{array}{l}\text { Local/ } \\
\text { Global }\end{array}$ & $\begin{array}{c}\text { Main } \\
\text { References }\end{array}$ \\
\hline $\begin{array}{l}\text { Connectivity } \\
\text { Indicator } \\
\text { (CI) }\end{array}$ & $\begin{array}{l}\quad C I=\sum(F * A S F * W D A) / 1000 \\
F: \text { frecquency } \\
\text { ASF: Available Seat per Flight } \\
\text { WDA: Weighting of Destination Airport }\end{array}$ & global & $\begin{array}{c}\text { Smyth and Pearce, } \\
2007 \\
{[10]}\end{array}$ \\
\hline $\begin{array}{c}\text { Airport } \\
\text { Connectivity } \\
\text { Quality Index } \\
\text { (ACQI) }\end{array}$ & $\begin{array}{l}\quad A C Q I=Q_{n s s}+S F * Q_{c s} \\
Q_{n n s}: \text { Quality of nonstop service } \\
S F: \text { Scaling Factor } \\
Q_{c s}: \text { Quality of connectivity service }\end{array}$ & local & $\begin{array}{c}\text { Wittman and } \\
\text { Swelbar, } 2013 \\
{[11]}\end{array}$ \\
\hline $\begin{array}{l}\text { Air } \\
\text { Connectivity } \\
\text { Index } \\
\text { (ACI) }\end{array}$ & $\begin{array}{l}\qquad A C I_{i}=\frac{D_{i}}{\sum_{j} B_{j}-B_{i}} \\
D_{i}: \text { the pull exercised by destinations in the } \\
\text { rest of the world on origin node } i \\
B_{i, j}: \text { the attractive potential of node } i, j\end{array}$ & global & $\begin{array}{c}\text { Arvis and } \\
\text { Shepherd, } 2011 \\
{[12]}\end{array}$ \\
\hline $\begin{array}{l}\text { Netscan } \\
\text { Connectivity } \\
\text { Units } \\
\left(\text { QUAL }_{\text {Netscan }}\right)\end{array}$ & $\begin{array}{l}\quad Q U A L_{\text {Netscan }}=1-\frac{P T T-N S T}{M A X T-N S T} \\
\text { PTT:perceived travel time }(h) \\
\text { NST: } n \text { on-stop travel time }(h) \\
\text { MAXT: } \text { maximum perceived travel time }(h)\end{array}$ & local & $\begin{array}{c}\text { Burghouwt and } \\
\text { Veldhuis, } 2006 \\
\text { [13] } \\
\text { Matsumoto, } 2008 \\
{[14]}\end{array}$ \\
\hline $\begin{array}{l}\text { Weghted } \\
\text { Connectivity } \\
\text { Number } \\
\left(f_{\mathrm{WCN}}\right)\end{array}$ & $\begin{array}{l}\qquad f_{W C N}=\tau * \delta \\
\tau: \text { connection time weight } \\
\delta: \text { routing factor weight }\end{array}$ & local & $\begin{array}{c}\text { Danesi, } 2006 \\
{[15]}\end{array}$ \\
\hline
\end{tabular}

According to some specialists, the definition of connectivity should include four properties: realistic, intensive, dimensionless and normalized, global [12]. Jenkins (2011) defines connectivity as a supply-side measure that indicates how-well integrated a specific airport in into a larger network. International Air Transport Association (IATA) was developed in 2007 a connectivity indicator based on the number of available seats per flight that are weighted by the size of the destination airport [16].

The recent research [5] defines the airport connectivity in terms of direct and indirect connectivity. The potential for growth at national level was highlighted by the evolution of the airport connectivity index that was increased with 38\% compared to 2007 (in monetary value, about 160 million EURO). 
Improvements in connectivity has brought benefits both to users (eg. reducing time spent in transit, increasing the frequency of service, improving the quality of service) and to wider economy (eg. increasing domestic market, strengthening territorial, economic and social cohesion, enhancing the level of productivity, enhancing the foreign direct investment) [17].

According to Oxford Economic Forecasting (2005), a 10\% increase in connectivity (relative to GDP) will raise the level of productivity in the economy by a little under $0,5 \%$ in the long run [18]. Another specialists estimate $0,07 \%$ for the elasticity between connectivity and long-run productivity [19].

\section{Model for assessing the investments in connectivity}

Model reviews the investment statements with multiple jump sources and identifies management solutions that increase the value of the investment opportunity. These jumps are considered independent of each other, each having random jump size and timing (Poisson distribution). Stochastic processes with a single source of discontinuity [20,21] or multiple sources of fluctuation, including specific cases of catastrophic events [22] are all approaches that influence the investment.

The proposed model continues the analysis of security investments [23], introducing the Poisson distribution, which is an appropriate model for the distribution of events with significant impact on the organization in a given period of time (corresponding investment). Thus, we can simulate the different values of the input parameters, the result of both investment projects and the optimal time to change the strategy. Positive and negative jumps, which have as a source significant events can be uncertain regarding timing and consequences of new information on technological advances, legislative changes, macroeconomic developments (e.g. inflation, oil prices) or connectivity trend index related to road and rail.

To assess the benefits (B), we propose a model where the intervention of arriving stochastic jumps has a constant probability per unit time. When a jump appears the benefit is changed with connectivity index CI calculated using the Smyth and Pearce model.

In the benefit equation (1), $\sigma$ is the volatility and $v$ is a random number generated using the standard normal distribution $\mathrm{N}(0,1)$, and $\mathrm{q}$ is the frequency of the rare event.

$$
B_{t+1}=B_{t}\left\{\left(1+C I_{t}\right)+\sigma v\left[1+\sum_{q=0}^{i}\left(e^{-\lambda} \frac{\lambda^{q}}{q !}\right)\right]\right\}
$$

The factor $v\left[1+\sum_{q=0}^{i}\left(e^{-\lambda} \frac{\lambda^{q}}{q !}\right)\right]$ represents the Wiener process that can affect the volatility $\sigma$.

This process was modeled using Poisson distribution (specific to rare events), and the sum represent the discretization of the integral that characterizes continuous time processes. Because the molecular motion of the particles is governed in terms of statistical normal distribution standard Wiener process affecting the same issue, these processes are also called Brownian motion.

The developed model allows a more accurate capture of the impact of sources of fluctuations in investment projects aimed at increasing connectivity. Neglecting the leap risk can lead to significant underestimation of the real value of investment opportunities, with negative consequences for decision-making. The model provides a realistic picture of the problems of air transport infrastructure investments for the following reasons: it uses the collective knowledge and experience, it incorporates the understanding of the "virtual 
marketplace" interactions, it introduces parameters associated with financial risk (volatility) and it depends on the level of progressive connectivity.

\section{A case study for Brasov airport}

The exemplification is made for the Brasov airport, based on estimates from the feasibility studies. To determine the evolution of the connectivity index the formula of probability complementary events is used (equation 2), where the calculated connectivity index, based on KPMG and Mott McDonald estimates, in the next 5 years is 0.15 .

$$
\sum_{k=0}^{4} C I(1-C I)^{k}=0.15
$$

The equation (2) allows to estimate connectivity index values for time intervals less or more than 5 years. Thus, the connectivity index for the next 3 or 10 years is 0.09 and respectively 0.28 . The result of the investment project benefits is calculated using the program Mathcad. Numerical computation highlights investment opportunities for different values of connectivity and volatility index. A summary of results is shown in Table 2.

Random normalized values obtained range between 1.84 and 0.212 , at an initial cost of investment normalized of 0.5 . Results are highly sensitive to the asymmetry of the jump size, which increases uncertainty, affecting the value of the investment opportunity.

The model was implemented in a simple, fast and efficient tool using the Mathcad program in a way in which data can be simulated based on two parameters: connectivity index and Wiener process factor.

Table 2. Normalized results of the benefit for different parameters values

\begin{tabular}{|c|c|c|c|c|c|c|}
\hline Parameters & $\begin{array}{l}\text { Time } \\
\text { (years) }\end{array}$ & $\begin{array}{c}\text { Benefit } \\
(B)\end{array}$ & Parameters & $\begin{array}{c}\text { Benefit } \\
(B)\end{array}$ & Parameters & $\begin{array}{c}\text { Benefit } \\
(B)\end{array}$ \\
\hline \multirow{5}{*}{$\begin{array}{c}\sigma=0.15 \\
\lambda=0.5\end{array}$} & 0 & 0.5 & \multirow{5}{*}{$\begin{array}{c}\sigma=0.20 \\
\lambda=0.5\end{array}$} & 0.5 & \multirow{5}{*}{$\begin{array}{c}\sigma=0.30 \\
\lambda=0.5\end{array}$} & 0.5 \\
\hline & 1 & 0.595 & & 0.877 & & 0.566 \\
\hline & 2 & 0.888 & & 1.42 & & 0.996 \\
\hline & 3 & 0.432 & & 0.164 & & 1.192 \\
\hline & 4 & 0.615 & & 0.212 & & 1.84 \\
\hline
\end{tabular}

Running successively allows assessment of sensitivity and a significant reduction of the uncertainties in the complex field of possible investments in air connectivity.

The model provides the decision maker a complete picture of the critical elements for this type of investment due to its agility and versatility.

The model can also be adapted for other examples of benefit assessment: airport security investments, where connectivity index is replaced with security risk index. 


\section{Conclusions}

Investment in infrastructure projects is an extremely complex problem for small airports because revenues are insufficient to cover the high operating costs and limited traffic. However, important economic can obtained benefits from aviation high level connectivity.

The research leads to the development of a framework for investment planning for a better use of funds by reducing operation costs and uncertainty for potential gains as well as substantiate predictions about the performance of the strategy. Limitations come from changing modeling assumptions calculation (complete system of markets and geometric Brownian motion asset prices) and the difficulty of quantifying the political, economic, industrial and technological uncertainties.

The inclusion of multiple sources of jump risk in a dynamic and realistic model, in which the investment is treated as a stochastic process, is an original contribution that provides for strategic decision makers particularly useful information both on the outcome of the investment project and on the optimal time to change the strategy.

The analysis of the results obtained by applying the model to a scenario involving the development of a new aviation infrastructure (Brasov airport) highlighted the following: confirming the forecasts of the investment performance and exploiting the uncertainties in the competitive market for potential gains.

Because very few studies/ international projects have included data on Romanian airports and a national study on the measurement of connectivity has not been accomplished so far, amid the rapid development of the national air transportation system (the emergence of new airports or developing existing ones), it should initiate a program to determine both investment efficiency indicator based on the level of benefits as well as the costs of connectivity.

This article was produced with the support of the documentation of the complex project, acronym MultiMonD2, code PNIII-P1-1.2-PCDDI-2017-0637, contract 33PCCDI/2018 funded by UEFISCDI.

\section{References}

1. Y. Li, B. James, R. Madhavan, J. Mahoney, "Real Options: Taking Stock and Looking Ahead", Adv. in Strat. Manag., 24, pp. 31-66 (2007)

2. N. Halpern, S. Brathen, "Impacts of airports on regional accessibility and social development”, Journal of Transport Geography, 19(6), pp. 1145-1154 (2011)

3. Government of Romania, "STRATEGY on the National Policy Framework Market Growth for Alternative Fuels in the Transport Sector and for the Installation of Relevant Infrastructure in Romania”, (March 2018)

4. EUROSTAT, "Tables, Graphs and Maps Interface (TGM). Air transport of passengers". Available on:

http://epp.eurostat.ec.europa.eu/portal/page/portal/transport/data/main_tables (accessed on March 2017)

5. Airport Council International, Airport Industry Connectivity Report 2017, Paris, p. 39 (2017)

6. UNCTAD, “World Investment Prospects Survey, 2009-2011”, UN Conference on Trade and Development (2009)

7. IBM, "Global Location Trends. Annual Report”, (October 2009)

8. S. D. Gleave, "The importance of improving International Air Connectivity for the North's economy. A study for the Northern Way”, (January 2011)

9. European Cities Monitor, "European Cities Monitor 2010 - Summary”, Cushman and Wakefield (2010) 
10. M. Smyth, B. Pearce, “Aviation Economic Benefits", IATA Economics Briefing, No.8 (2007)

11. M. Wittman, W. Swelbar, "Trends and Market Forces Shaping Small Community Air Service in the United States", MIT International Center for Air Transportation Report No. ICAT-2013-02 (2013)

12. J.F. Arvis, B. Shepherd, "The Air Connectivity Index Measuring Integration in the Global Air Transport Network. Policy Research Working Paper 5722”, The World Bank (2011)

13. G. Burghouwt, J. Veldhuis, "The competitive position of hub airports in the Transatlantic market", Journal of Air Transportation, 11(1), pp. 1071-30 (2006)

14. H. Matsumoto, G. Burghouwt, J. de Wit, J. Veldhuis, "Network performance, hub connectivity potential, and competitive position of primary airports in Asia/Pacific region", Air Transport Research Society Conference, Athens (2008)

15. A. Danesi, "Spatial concentration, temporal co-ordination and profitability of airline hub-and-spoke networks", Ingineria dei Transporti, Bologna (2006)

16. J.J. Jenkins, "The Evolution of Passenger Accessibility in the US Airline Industry, 1980-2010”, Massachusetts Institute of Technology, Cambridge, MA. Masters Thesis (2011)

17. Oxford Economics, "Economic Benefits from Air Transport in Romania. Romania country report" (2011)

18. InterVISTAS, “Estimating Air Travel Demand Elasticities”, InterVISTAS Consulting Inc, $2007 . \quad$ Available at http://www.iata.org/whatwedo/Documents/economics/Intervistas_Elasticity_Study_20 07.pdf (accessed on October 2016)

19. Oxford Economic Forecasting, "Trade liberalization and CAP reform in the EU", Oxford, (October 2005)

20. D. Mauer, S. Ott, "Investment under uncertainty: The case of replacement investment decisions", Journal of Financial and Quantitative Analysis, 30, pp. 581-605 (1995)

21. E. Pennings, O. Lint, "The option value of advanced $R \& D$ ", European Journal of Operations Research, 103, pp. 83-94 (1997)

22. S. Martzoukos, L. Trigeorgis, "Real (investment) options with multiple sources of rare events", European Journal of Operational Research, 136, pp. 696-706 (2002)

23. C. Cioaca, M. Boscoianu, "Model of Assessing the Impact of Rare Events in Aviation Security Investments Projects”, Applied Mechanics and Materials, Vol. 555, pp. 11-17 (2014) 